\title{
9 Routes in Innate Immunity Evolution: Galectins and Rhamnose-binding Lectins in Ascidians
}

\author{
Loriano Ballarin, ${ }^{1}$ Matteo Cammarata, ${ }^{2}$ Nicola Franchi ${ }^{1}$ \\ and Nicolò Parrinello ${ }^{2}$ \\ ${ }^{1}$ Department of Biology, University of Padova, Padova, Italy \\ ${ }^{2}$ Department of Environmental Biology and Biodiversity, University of Palermo, \\ Palermo, Italy
}

\subsection{ANIMAL LECTINS}

The term 'lectin' is commonly used to encompass a wide variety of carbohydrate-binding proteins, widely distributed in viruses, prokaryotes and eucaryotes (Vasta \& Ahmed, 2008). The first animal lectins were isolated by Noguchi in early 1900 from Limulus polyphemus and Homarus americanus; many years later, Watkins \& Morgan (1952) proposed a sugar-specific binding (L-fucose) property for the eel lectin. Animal lectins are grouped in various molecular families, differing in carbohydrate-recognition domain (CRD) structure and organization (Gabius, 1997; Kilpatrick, 2002; Loris, 2002; Vasta et al., 2004). They are involved in a variety of key biological processes, ranging from development (Kaltner \& Stierstorfer, 1998; Kilpatrick, 2002) to immune responses (Arason, 1996; Vasta et al., 1994). Protein-carbohydrate interactions are the basis of a mechanism for signaling functions, cell communication and self-non-self recognitions and are critical in the establishment and maintenance of highly specific mutualistic associations in organism-microbe complexes (Sharon \& Lis, 1993). In this respect, mutual benefit (symbiosis or commensalism) depends on the maintenance of a tightly regulated balance, whereas colonization of tissues beneficial to the microbe can lead to the loss of host fitness (pathogenesis), unless host-defense responses are able to eliminate the foreignness (Casadevall \& Pirofski, 2000). Microheterogeneity, originating from multiple lectin gene copies, allelic variation or post-translational modifications of the gene products, expands the molecular diversity and recognition capabilities. The molecular repertoire may provide a broad non-self-recognition capacity for an efficient innate immune recognition system based on recognition of carbohydrate moieties.

Galectins, rhamnose-binding lectins, C-type lectins, fucolectins, P-type lectins and L-type lectins are some examples of animal lectins (Kilpatrick, 2002; López et al., 2011; Shirai et al., 2009).

\subsection{ASCIDIANS}

Ascidians are invertebrate chordates constituting the most-studied and richest in species class of the subphylum Tunicata or Urochordata, which, together with Cephalochordata

Marine Proteins and Peptides: Biological Activities and Applications, First Edition. Edited by Se-Kwon Kim. (c) 2013 John Wiley \& Sons, Ltd. Published 2013 by John Wiley \& Sons, Ltd. 
and Vertebrata, forms the phylum Chordata. The body of the sessile adult is lined by an epidermis and covered with the tunic. The chordate features-notochord, neural tube, muscular tail and pharynx provided with gill slits - are present in the swimming larva and disappear at metamorphosis, with the exception of the pharynx, which extends into the body (Berril, 1955; Burighel \& Cloney, 1997). Recent phylogenetic analysis suggests that ascidian could be the sister group of vertebrates (Delsuc, 2006; Tsagkogeorga et al., 2009).

The solitary species Ciona intestinalis and the colonial species Botryllus schlosseri are important model organisms for developmental and evolutionary biology studies, including immunobiology. C. intestinalis is widely distributed in the coastal areas of all temperate seas and grows in dense aggregations on any floating or submerged substrate or other fouling organism (Fig. 9.1a). It is an insufficient hermaphroditic broadcast spawner, with a cylindrical soft body attached on a substrate by the posterior end, while at the anterior side the oral and atrial siphons provide for the water flux through the pharynx. The pharyngeal sac occupies a wide body region and is formed by bars and vessels containing hemolymph and hemopoietic nodules. Undifferentiated cells can proliferate and differentiate the hemocyte lines (Peddie et al., 1995). The genome has been fully sequenced and many transcript sequences of various developmental stages, from embryo to adult, are available in databases (http://genome.jgi-psf.org/Cioin2/Cioin2.home.html).

The compound ascidian Botryllus schlosseri (Fig. 9.1b) is a reliable model organism for a variety of studies, ranging from sexual and asexual reproduction to immunobiology (Manni et al., 2007). The complete genome is not yet available and its transcriptome is less known than that of Ciona; however, the number of expressed sequence tags (ESTs) available in databases is progressively increasing due to the efforts of various research groups. Zooid individuals are grouped in star-shaped systems, are enveloped by a common tunic and share the colonial vascular system, with peripheral and radial vessels connecting zooids, buds and budlets. Colonies reproduce asexually and three blastogenetic generations are usually present in a colony: adult, filtering zooids; buds on zooids; and budlets on buds (Manni et al., 2007). A weekly (at $20^{\circ} \mathrm{C}$ ) generation change or take-over (TO) allows the cyclical renewal of the colony. Colonial developmental phases lying more than 1 day from the preceding and following TO are collectively referred to as 'midcycle' (MC) (Lauzon et al., 1992; Manni et al., 2007).

\subsubsection{Inflammatory Responses of the Solitary Ascidian C. intestinalis}

Various hemocyte types circulating in the pharynx vessels and scattered in a not-vascularized tunic matrix are involved in $C$. intestinalis innate immunity. Particulate or soluble materials inoculated into the tunic challenge a local inflammatory-like response due to a massive infiltration of hemocytes, which release several products and encapsulate the affected tissue (Arizza \& Parrinello, 2009; Cammarata \& Parrinello, 2009; Cammarata et al., 2008; Parrinello, 1981; Parrinello et al., 1984a,1984b). In addition, hemocytes are protagonists of the pharynx inflammatory reaction due to lipopolysaccharide (LPS) inoculation (Parrinello, 1996; Parrinello et al., 2007; Pinto et al., 2003; Shida et al., 2003; Vizzini et al., 2007, Vizzini et al., 2008). Humoral factors named 'tunicate-cytokines' can stimulate cell proliferation and modulate hemocyte activities (Beschin et al., 2001; Parrinello et al., 2007).

Recent progress in the genome sequencing and cDNA/EST production (Azumi et al., 2003; Terajima et al., 2003a,b) derived from hemocytes (Shida et al., 2003; Terajima et al., 2003) has contributed to the study of immunity-gene expression and function. Genes for 


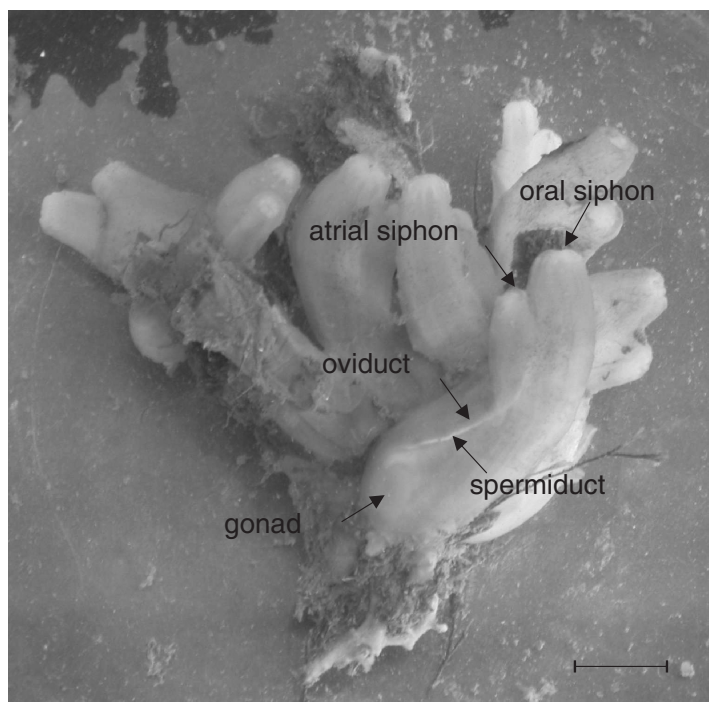

(a)

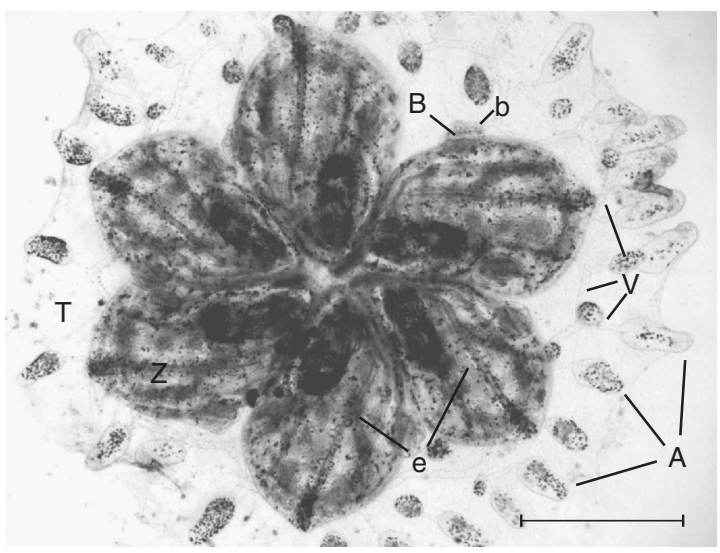

(b)

Fig. 9.1 (a) Aggregation of $C$. intestinalis specimens. Scale bar: $2 \mathrm{~cm}$. (b) Ventral view of a B. schlosseri colony. Zooids $(\mathbf{Z})$, buds on zooids $(\mathbf{B})$ and budlets on buds $(\mathbf{b})$ are embedded in the common tunic $(\mathbf{T})$. The endostyle (e) is clearly visible, and many vessels $(\mathbf{V})$ of the common circulation connecting all the zooids can be seen; along the periphery they end with blind ampullae (A). Scale bar: $1 \mathrm{~mm}$.

tumor necrosis factor-like proteins ( $\mathrm{CiTNF} \alpha)$ (Parrinello et al., 2008), C3-like complement factor and $\mathrm{CiC} 3-1 \mathrm{a}-$ like fragment $(\mathrm{CiC} 3$ and $\mathrm{CiC} 3 \mathrm{a}$ ) (Pinto et al., 2003), mannose-binding lectin-like (CiMBL, Bonura et al., 2009) and a component of the CAP protein family (cysteine-rich secretory proteins, antigen 5 and pathogenesis-related 1 proteins) can be promptly expressed following LPS inoculation (CiCAP) (Bonura et al., 2010).

\subsubsection{B. schlosseri Immune Responses}

B. schlosseri immune responses include phagocytosis and cytotoxicity, mediated by circulating immunocytes, and finely regulated by cytokines and lectins released by 
immunocytes themselves (Ballarin, 2008; Menin \& Ballarin, 2008). In addition, an inflammatory reaction, including the selective recruitment, extravasation and degranulation of cytotoxic cells, with the consequent release of phenoloxidase, a cytotoxic enzyme, and of its polyphenol substrata, is usually observed during the nonfusion reaction between contacting, genetically incompatible colonies (Ballarin et al., 2008).

\subsubsection{Ascidian Lectins}

A wide literature reports on lectin families in tunicates. Multiple lectins of diverse specificities indicate that a very complex lectin repertoire is involved in innate immunity (Queseberry et al., 2003; Sharon \& Lis, 2007). Several C-type (Ca-dependent) lectins, both soluble and integral membrane proteins, have been found in ascidians, including mannosebinding lectins, provided with a collectin-like structure, and selectins (Bonura et al., 2009; Green et al., 2006; Raftos et al., 2001; Vasta et al., 1999). A ficolin homolog functions like mammalian collectins (Sekine et al., 2001); pentraxins are acute-phase proteins that, like MBL and other collectins, have opsonic, mitogenic and complement-activation properties (Vasta et al., 1986a,b). In ascidians, a conserved lectin-dependent pathway of complement may be activated and a C3-like component is cleaved by lectin-associated serine proteases (CiMASPs) (Ji et al., 1997; Nonaka \& Azumi, 1999; Marino et al., 2002; Miyazawa et al., 2001; Sekine et al., 2001; Vasta et al., 1999). The CiC3a fragment exerts in vitro chemotactic activity toward hemocytes (Pinto et al., 2003). Interestingly, a B. schlosseri lectin type contains both a C-type lectin domain and an immunoglobulin-like domain (Pancer et al., 1997), similar to the fibrinogen-related proteins from molluscs (FREPS) involved in defense (Adema et al., 1997). Finally, a lytic mechanism based on soluble phospholypases A2 (sPLA2) and $\beta$-galactoside-specific lectins is exerted by $C$. intestinalis hemocytes against the K562 cell line and mammalian erythrocytes (Arizza et al., 2011).

\subsection{GALECTINS}

Galectins are widely distributed throughout the animal kingdom (from protists to mammals) and are expressed in a variety of organs and tissues (Cooper \& Barondes, 1999). They form a molecular family composed of $\mathrm{Ca}^{+2}$-independent soluble lectins (also known as galaptins or S-lectins) - defined by a conserved CRD that binds $\beta$-galactoside-containing glycans - and present a conserved $\beta$-sandwich structure formed by six S1-S6 and five F1-F5 strand sheets. The S4-S6 strands contain the conserved carbohydrate-binding amino acids (Hirabayashi \& Kasai, 1993; Loris, 2002; Rabinovich et al., 2007; Rapoport et al., 2008; Rini \& Lobsanov, 1999).

Galectins are probably the most conserved and ubiquitous lectin family. The first galectin was identified and characterized from the electric organs of the eel Electrophorus electricus (Teichberg et al., 1975), and more than 15 galectins have been identified in mammals involved in the regulation of innate and adaptive immune responses. Members of the galectin family have been found in birds, amphibians, fish, nematodes, sponges and some fungi (Houzelstein et al., 2004; Vasta, 2012).

Galectins are nonglycosilated proteins that lack a signal peptide and share a conserved sequence motif in their CRDs consisting of about 130 amino acid residues (Ogawa et al., 2011). They bind to $\beta$-galactosides (such as lactose and $\mathrm{N}$-acetyllactosamine) either in free form or as components of glycoproteins or glycolipids. Based on their structural 
features, galectins can be classified into three subfamilies: prototype (mono-CRD, single carbohydrate-binding domain), which exists as monomer; tandem-repeat type (bi-CRD; two distinct carbohydrate-binding domains on a single chain, joined by a random-coil linker); and chimera type (carbohydrate-binding domain and a regulatory N-terminal domain with collagen-like sequences). Functional multivalency, allowing the crosslinking of glycan ligands, improves galectin activity and cellular effects. A noncovalently linked dimeric form of the prototype galectin is required for effective binding and signaling through the cell surface (Levroney et al., 2005). The activity of tandem-repeat galectins results from the constitutive bivalency, but the ability of the flexible linker domain to form dimers may increase their potency (Earl et al., 2011). It is maintained that association in the regulatory domain of chimera type in the presence of multivalent carbohydrate ligands could result in oligomerization (Ahmad et al., 2004). Garner \& Baum (2008) proposed a model in which cell function may be 'fine-tuned' by modulating galectins, affecting membrane-domain organization and signaling-threshold setting, and increasing receptor residency time at the cell surface. In addition, cell function can be modulated by protein glycosylation, in which galectins regulate apical sorting of glycoproteins (Rodriguez et al., 1999).

These galectin structures are conserved among invertebrates and vertebrates, although the number of genes can vary markedly even between closely related species (Cooper, 2002; Kaltner \& Gabius, 2012; Vasta, 2012). They play important roles in morphogenesis, cell proliferation control, cell death, tumor progression (modulating tumor growth and metastasis) and diverse other pathological processes (Brewer et al., 2002; Gabius \& Wu, 2008; Paulson et al., 2006; Sato \& Rabinovich, 2008). Galectins have been shown to participate in a plethora of immune responses by acting intracellularly and extracellularly as cytokines, growth-inhibitory factors, death triggers and survival inducers (Liu et al., 2008; Sato \& Rabinovich, 2008). In this regard, they have been related to inflammatory responses, including a direct interaction with pathogens and modulation of phagocyte function (Vasta, 2012). Extracellular galectins exhibit low-affinity bivalent or multivalent interactions with glycans and form multivalent complexes with cell-surface glycoprotein receptors (Garner \& Baum 2008) that can induce various cellular responses and regulate a variety of cell functions, including proliferation, cell adhesion, migration, cell motility and apoptosis (Hernandez \& Baum, 2002; Rabinovich \& Toscano, 2009). Intracellular galectins can participate in signaling pathways and alter biological responses, including cell differentiation, production of cytokines and other inflammatory mediators (Liu et al., 2012). Galectin involvement in some in vivo processes has been discovered, or supported through studies of genetically engineered mouse strains, each deficient in a given galectin. Current evidence also suggests that galectins may be therapeutic targets or employed as therapeutic agents (Parsonage et al., 2006; Yang et al., 2008).

\subsubsection{Molecular Features, Structure and Evolution of C. intestinalis Galectins}

In order to elucidate the chordate galectin evolutionary history, Houzelstein et al. (2004) exploited the location of two galectin-encoding genes (CiLgals-a and CiLgals-b) on the EST and JGI $C$. intestinalis database, the exon-intron organization and the sequence comparison of CRDs. The N-terminal and C-terminal CRDs may have diversified into two different subtypes (F4-CRD and F3-CRD), defined by exon-intron structures that are always encoded by three exons and identified on the basis of the second CRD exon 
LGALS4 human

\begin{tabular}{|l|lllll|}
\hline & & & & & $1100 \mathrm{nt}$ \\
\hline S3 & F4 & S3 & F3 &
\end{tabular}

CiLgals a

\begin{tabular}{|l|l|l|lr|}
\hline & & & & $1285 \mathrm{nt}$ \\
\hline S3 & F4 & S3 & F3 & \\
\hline
\end{tabular}

CiLgals $b$

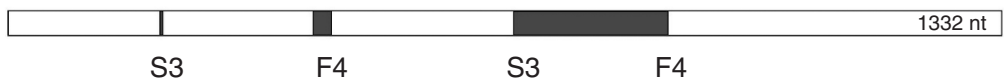

Fig. 9.2 Comparison of the typical human bi-CRD with $C$. intestinalis gene organization. Exons are represented as boxes. The $\mathrm{W}$ exons, which contain the highly conserved tryptophan residue of galectins, are either dark gray where they encode S3 to F4 sequences (F4 subtype), or are light gray where they encode $\mathrm{S} 3$ to $\mathrm{F} 3$ sequences (F3 subtype).

(Fig. 9.2), the F4-CRDs ending within the sequence encoding the F4 $\beta$ strand (S3-F4) and the F3-CRDs within the sequence encoding the F3 $\beta$ strand (S3-F3). The phylogenetic tree built with the deduced amino acid sequences suggests that the ascidian biCRD galectin gene originated from a first duplication of a mono-CRD gene, probably before chordate evolution. Various domain structures, found in mollusks and hydrozoans, suggest that an ancestor CRD gene contributed in proteins with diversified functions (Fig. 9.3). An oyster (Crassostrea virginica) galectin, involved in defense, contains four galectin CRDs in the

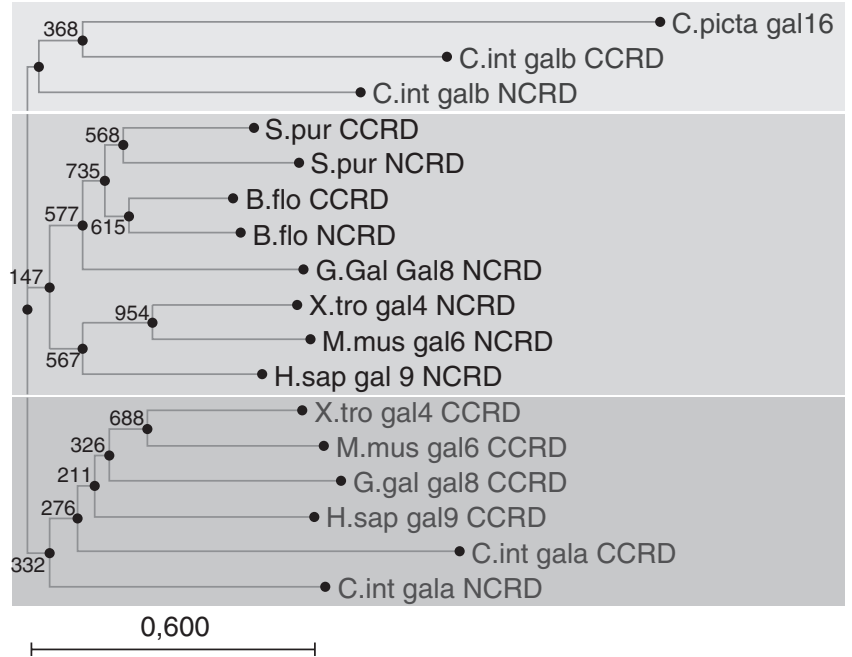

Fig. 9.3 Phylogenetic tree of CRDs from Cilgals-a, Cilgals-b, vertebrate bi-CRD galectins amino acid sequences (C. picta: Clavelina picta; C. int: Ciona intestinalis; S. pur; Strongylocentrotus purpuratus; B. flo: Branchiostoma floridae; G. gal: Gallus gallus; X. tro: Xenopus tropicalis; M. mus: Mus musculus; H. sap: Homo sapiens). The tree was constructed by the neighbor-joining method and bootstrap analysis. The bootstrap value indicates the percentage of time that a particular node occurred in 1000 trees generated by bootstrapping the galectin CRD sequences. Bar 0.600 (number of amino acid-residue substitutions for site). 
same polypeptide chain (Tasumi \& Vasta, 2007). A nematocyst tubule nematogalectin, with an N-terminal GlyXY domain, can form a collagen triple helix followed by galectin CRD (Hwang et al., 2010). Galectins isolated from the sponge Geodia cydonium form tetramers (Hirabayashi et al., 2002).

The sequence of duplication and divergence events could explain the different chordate galectins (Cooper et al., 2002; Houzelstein et al., 2004), while multiple lectin gene copies, allelic variation or post-translational modifications of the gene products expand the molecular diversity and recognition capabilities. Vizzini et al. (2011) analyzed the sequenced cDNA and CRD sequences and supported the predicted bi-CRD CiLgals-a and CiLgals-b gene organization and the chromosome localization (chromosome $4 \mathrm{q}$ and chromosome $6 \mathrm{q}$, respectively). The $C i$ Lgals-a transcript (1285 nt) encodes a 289-amino acid sequence with a deduced molecular size of $32 \mathrm{kDa}$, and the CiLgals-b transcript (1332 nt) encodes a 318-amino acid sequence $(37 \mathrm{kDa})$. Like vertebrate cytosolic galectins, they do not contain a signal peptide and presumably are released through a nonclassical secretory pathway (Vizzini et al., 2011). The major sequence-similarity and identity percentages were found with chicken galectin 8 (CiLgals-a) and mouse galectin 6 (CiLgals-b).

The $C i$ Lgals-a exhibits the F4-CRD-linkers-F3-CRD arrangement typical of the vertebrate Bi-CRD Lgals genes. Otherwise, the CiLgal-b presents a specific F4-CRD-linker-F4CRD organization. Moreover, the $C i$ Lgals-a and $C i$ Lgals-b CRD sequences were aligned with F4-CRD-linkers-F3-CRD vertebrate bi-CRD galectins, the cephalochordate Branchiostoma floridae, the echinoderm Strongylocentrotus purpuratus gal RL30 galectin and the ascidian Clavelina picta mono-CRD gal16 (Vizzini et al., 2011). The phylogenetic tree shows that vertebrate N-CRDs and C-CRDs are grouped into two distinct clusters, indicating an early domain divergence after a duplication event. Interestingly, the divergence between vertebrate $\mathrm{N}-\mathrm{CRD}$ and $\mathrm{C}-\mathrm{CRD}$ was greater than that between N-CRD and C-CRD of the examined deuterostome invertebrates. Moreover, the N-CRD cluster includes both $S$. purpuratus and B. floridae N-CRD and C-CRD, while the C-CRD lineage includes $C i$ Lgals-a C-CRD and N-CRD. Both $C i$ Lgals-b C-CRD and N-CRDs are derived from an S3-F4 gene organization (F4-CRD-linker-F4-CRD). The close relationship between CiLgals-b and the sequenced mono-CRD of Clavelina picta (F4 subtype) supports a duplication event for the ascidian bi-CRD galectin origin. On the basis of the known galectin molecular structures, molecular models (homology-modeling process) have been performed and the following overlapping was found (Fig. 9.4): the CiLgalsa N-CRD can be superimposed on the human Gal 9C-CRD (about 40\% identity); the CiLgals-a C-CRD on the human Gal 3 C-CRD (30\% identity); the CiLgals-b N-CRD on the human Gal 9N-CRD (30\% identity); the CiLgals-b C-CRD on the human Gal $4 \mathrm{C}$ CRD (about $28 \%$ identity). This procedure disclosed that the CiLgals-a and b domains and human CRDs share a structural model that includes two antiparallel $\beta$-sheets composed of five and six $\beta$-strands. The CiLgals-a N-CRD and C-CRD, as well as the CiLgalsb $\mathrm{N}$-CRD structures, appear to be suitable for binding to $\beta$-galactosides. On the other hand, the CiLgals-b C-CRD is so divergent that a distinct functional role cannot be excluded. In addition, while the CiLgals-a can be superimposed on the gal 4 (2wsuC) domain, the CiLgals-b cannot. Finally, $C i$ Lgals-a and $C i$ Lgals-b can form distinct oligomers. Specific antibodies identified two different subunits of $42 \mathrm{kDa}$ (CiLgals-a) and $38 \mathrm{kDa}$ (CiLgalsb), which could form 73 and $70 \mathrm{kDa}$ dimers, respectively. Protein-protein interaction in $\mathrm{Ci}$ Lgals oligomerization is an intriguing issue that merits further investigation. In this respect, multiple galectins have been found in Clavelina picta, with various subunit sizes (4, 15, 33 and $37 \mathrm{kDa})$ (Ahmed \& Vasta, 1994b). 


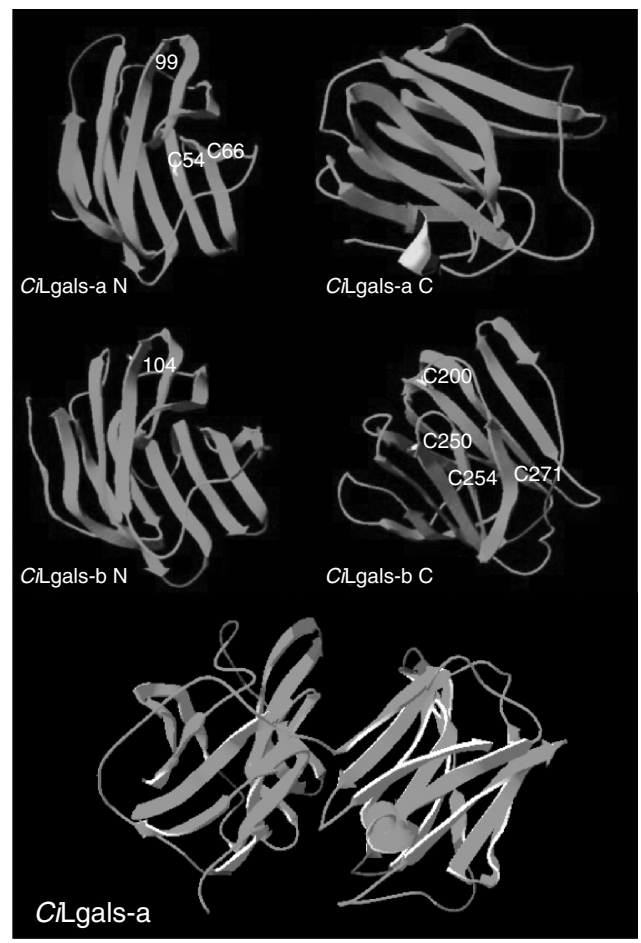

Fig. 9.4 Cilgals-a, Cilgals-b CRDs of $C$. intestinalis, modeled with the more structural significant template of galectin domains. Cilgals-a N terminal: 3nv1A (Human Gal-9 C-Terminal CRD 39.85\% identity); Cilgals-a C terminal: 2xg3A (Human Gal-3 29.71\% identity); Cilgals-b N terminal: 2zhnA (Human Gal-9 N-Terminal CRD (30.35\% identity); Cilgals-b C terminal 1x50A (Human Gal-4 C-Terminal CRD $27.40 \%$ identity). All sequence (Human Gal-4 C 2wsuC). Cysteins are indicated by position numbers.

\subsubsection{Involvement of Galectins in C. intestinalis Inflammatory Response}

It is known that, in vertebrate organisms, pathogens upregulate the expression of galectin genes (Klyosov, 2008; Sato \& Rabinovich, 2008). LPS locally inoculated into the C. intestinalis body wall permeates the pharynx tissue surrounding the inoculation site and stimulates a local inflammatory reaction, which rapidly upregulates the expression of the CiLgals-a and b genes. Real-time polymerase chain reaction (PCR), in situ hybridization and immunohistochemistry disclosed that, in the pharynx, both galectins are constitutively expressed at a low level. However, they are inducible; the expression is little increased as an effect of the medium inoculation, but significantly enhanced by LPS inoculation. The CiLgals-a gene is highly expressed, reaching its maximum level within 24 hours post inoculation. Conversely, the CiLgals-b reaches the highest expression within 1 hour, then decreases, with a secondary increase at 24 hours post inoculation. Afterwards ( 72 hours), both CiLgals-a and CiLgals-b gene expressions lowered at control levels. In situ hybridization assays showed that both genes were expressed by two granulocyte types (unilocuolar and multilocuolar hemocytes) (Fig. 9.5). The specific riboprobes are localized in the nucleus and in the surrounding cytoplasm, while the specific antibodies show that both the galectins are mainly associated with 


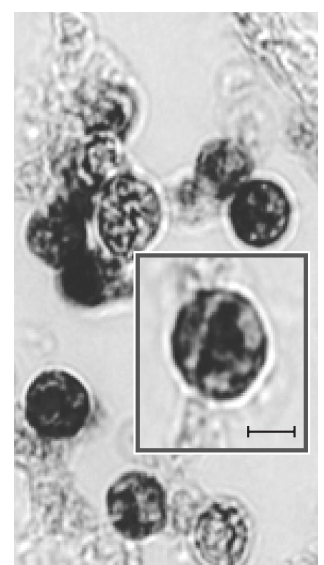

(a)

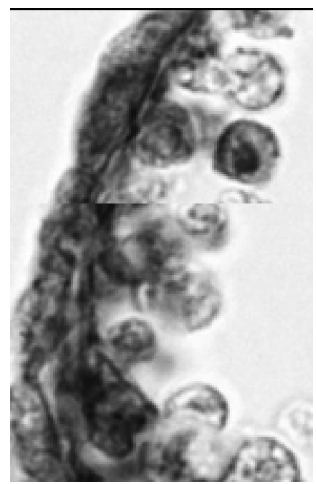

(c)

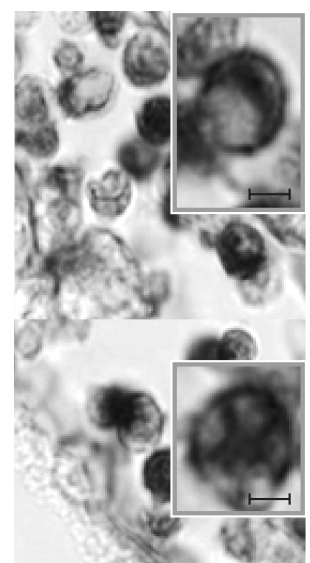

(b)

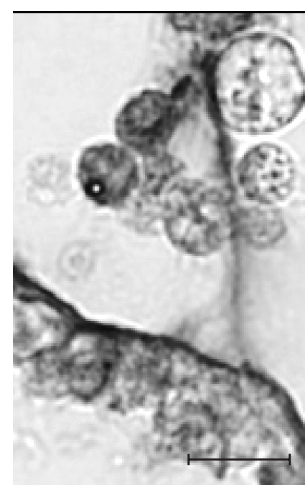

(d)

Fig. 9.5 Histological sections from $C$. intestinalis pharynx. In situ hybridization with Cilgals-a (a) and Cilgals-b (b) ripoboprobe. (a,b) Immunohistochemistry with anti-Cilgals-a (c) and anti-Cilgals-b (d) antibody. (c) Sham ascidian at 24 hours after inoculation with marine solution; hemocytes at 24 hours. (d) Sham ascidian at 24 hours after inoculation with marine solution; hemocytes at 24 hours. Scale bar: $10 \mu \mathrm{m}$; insets: $5 \mu \mathrm{m}$.

granule and nucleus envelopes, and less frequently are components of granule content (Fig. 9.5). Immunoblotting analysis disclosed CiLgal-a (74 and $43 \mathrm{kDa}$ ) and CiLgal-b (71 and $39 \mathrm{kDa}$ ) in the pharynx-extract supernatants sampled at 24 hours post LPS inoculation. In addition, both galectins appeared to be components of the endothelium basal membrane. The amino acid sequence alignments also disclosed the vertebrate galectin sequence signature (HNPRN and WG-EE). In the CiLgals-a, the seven key residues known to be directly involved in galactoside binding ( $\mathrm{H}-\mathrm{N}-\mathrm{R} \mathrm{N} \mathrm{W}$ - -EE) are conserved in the N-CRD, whereas in the C-CRD only one key residue is substituted with a conservative amino acid. The $C i$ Lgals-b contains only five conserved key residues in the N-CRD, whereas the CiLgals-b C-CRD displays only three out of seven key amino acids. Due to the differences between signature sequences involved in sugar binding, the possibility exists that $\mathrm{CiLgals-b}$ has a minor role in pharynx inflammatory response, as also indicated by the minor immunohistochemical staining with anti-CiLgals-b antibody. 
Although it has not been clarified whether in the hemolymph serum various types of D-galactose-specific lectin might be opsonins, galectin-like molecules $\left(\mathrm{Ca}^{+2}\right.$-independent binding and D-galactoside specificity) with opsonic properties can be enhanced in response to LPS (Parrinello et al., 2007). Finally, it is of interest that inducible galectins may evoke danger signals (alarmins) in inflammatory responses (Sato \& Rabinovich, 2008; Sato et al., 2008).

\subsection{RHAMNOSE-BINDING LECTINS}

More than 20 years ago, Ozeki et al. (1991) described a new lectin, named SUEL, with specificity for D-galactosides, which is abundant in the eggs of the sea urchin Anthocidaris crassispina and is now recognized as the first described member of a new family of animal lectins, the rhamnose-binding lectins (RBLs). RBLs are $\mathrm{Ca}^{2+}$-independent lectins with specificity for rhamnose and galactosides (galactose can easily antagonize rhamnose and bind the RBL CRD), which are particularly abundant in teleosts and other aquatic invertebrate species, such as annelids and bivalves among protostomes and ascidians among chordates (Ogawa et al., 2011). All RBLs do not show amino acid sequence similarity to known lectin families, do not require $\mathrm{Ca}^{2+}$ for carbohydrate recognition and share the presence of one or multiple CRDs with a unique $\alpha / \beta$ fold, about 100 amino acids long, with eight highly conserved cysteine residues engaged in four disulfide bridges with characteristic topology (Jimbo et al., 2007; Terada et al., 2007). In addition, conserved motifs, such as YGR, DPC and KYL, are also found in their CRDs (Terada et al., 2007).

As regards the role of RBLs, it has been proposed that they are involved in the regulation of carbohydrate metabolism, control of fertilization and cytotoxicity. In addition, an enhancing effect on cell proliferation has been reported for RBLs of human dermal fibroblasts (Faury et al., 2008), whereas fish lectins increase their expression in response to inflammatory stimuli, enhance phagocytosis, acting as opsonins, and induce the synthesis and release of pro-inflammatory cytokines (Ji et al., 2009; Lam \& Ng 2002; Ogawa et al., 2011; Tateno et al., 2002a; Terada et al., 2007; Watanabe et al., 2009).

The ability to recognize and bind lipopolysaccharisides and lipoteichoic acid and agglutinate both Gram-positive and Gram-negative bacteria has been described in trout RBLs, suggesting an antibacterial activity (Matsui et al., 1994; Tateno et al., 2002a). In addition, RBLs have also been found in the cortex of teleost eggs, as well as in the skin mucus, further confirming their protective role. A putative natural ligand of fish RBL is the glycosphingolipid globotriasylceramide (Gb3), abundant in membrane lipid rafts (Ogawa et al., 2011; Watanabe et al., 2009).

The RBL CRD appeared early in metazoan evolution and is found in a variety of proteins with different domain architectures, from basal metazoans (e.g. cnidarian rhamnospondins) to mammals (e.g. polycystic kidney disease 1-like, axon-guidance receptor EVA-1 and latrophilin); all these proteins and RBLs constitute the RBL superfamily of proteins, which contain RBL CRDs in their sequences as a domain structure (López et al., 2011; Ogawa et al., 2011; Schwarz et al., 2007; Vakonakis et al., 2008).

\subsubsection{RBLs in B. schlosseri: Biochemical and Molecular Features}

The hemolymph of the colonial ascidian B. schlosseri contains soluble lectin(s) able to agglutinate yeast cells and rabbit erythrocytes (Ballarin et al., 1999). In an attempt to 
characterize this material and obtain the amino acid and nucleotide sequences of the protein(s) and the transcript(s), a full-length cDNA library from Botryllus colonies was prepared, from which five sequences were identified, each with a single, complete open reading frame, representing five isoforms of a novel ascidian RBL, referred to as BsRBL. All of them encoded putative proteins of 118 amino acids, belonging to type-V RBLs (Watanabe et al., 2009), containing a single CRD of 81 amino acids. The predicted protein sequences showed full conservation of the eight cysteines involved in the four disulfide bridges, as well as of the YGR, DPC and KYL motifs which characterize RBL CRDs (Fig. 9.6a). Four of the five sequences were identified and confirmed by biochemical analysis, after purification of colony homogenates. The positions of the disulfide bonds were verified after sequential hydrolysis with V8-endoprotease and formic acid and MS analysis (Fig. 9.6b) (Gasparini et al., 2008).

The five isoforms differ in a few of their amino acids and have slightly different sizes, as indicated by MS and HLPC analysis. Electrophoretic analysis under reducing conditions showed a single band of $11 \mathrm{kDa}$, in good agreement with the expected molecular masses of BsRBLs, whereas bands of 6, 12.4 and $17.5 \mathrm{kDa}$ were observable under nonreducing conditions (Fig. 9.6c), which suggests the presence of oligomers, with the three bands representing the monomeric, the dimeric and the trimeric form, respectively.

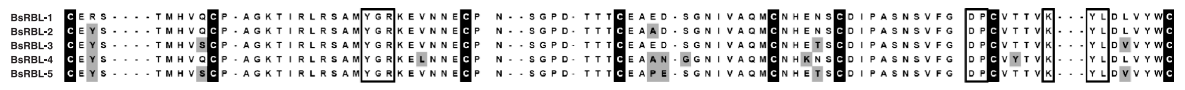

(a)

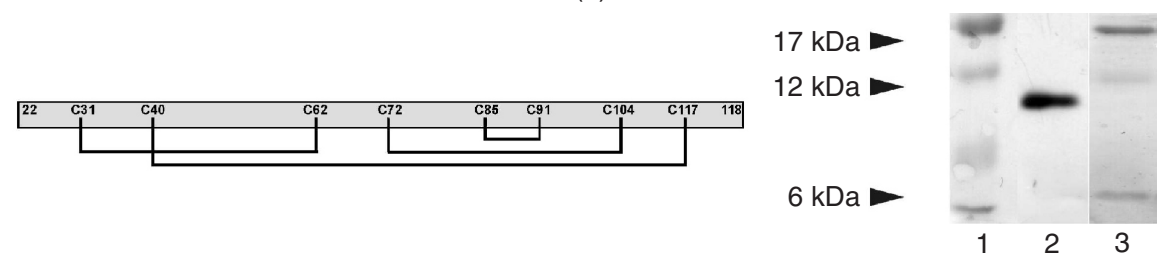

(b)

(c)

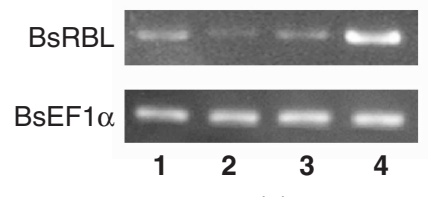

(d)

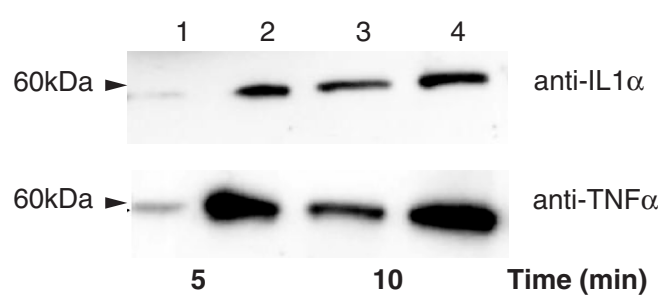

(e)

Fig. 9.6 (a) Multiple alignment of the five known isoforms of BsRBL. Conserved cysteine residues are shaded black, amino acid variations are shaded grey, boxes indicate conserved motifs. (b) Aligmnent of the five isoforms of BsRBL, showing the locations of the disulfide bonds. Grey area above the alignment: CRD; grey area below the alignment: $\mathrm{N}$-terminal signal peptide. Highly conserved motifs of RBLs are boxed. (c) SDS-PAGE analysis of purified BsRBL. Lane 1: reference molecular weights; lane 2: strong denaturing conditions; lane 3: mild denaturing conditions. (d) Semiquantitative-PCR analysis of BsRBL expression during colonial blastogenetic cycle, compared with $B s E F 1 \alpha$ expression. Lane 1 : beginning of a new cycle; lanes 2 and 3: midcycle (MC); lane 4: take-over. (e) Immunoblot analysis, with anti-IL $1 \alpha$ and anti-TNF $\alpha$ antibodies, of culture media from haemocytes incubated for 5 and 10 minutes in the presence (lanes 2 and 4 ) or absence (lanes 1 and 3) of BsRBL. 
The formation of oligomers was reported in other RBLs ( $\mathrm{Ng}$ et al., 2003; Ozaki et al., 1983; Ozeki et al., 1991; Tateno et al., 1998) and is required in order to explain the agglutinating activity of BsRBLs, which, like SUEL, are endowed of a single CRD. However, unlike SUEL, all the cysteines of BsRBLs are involved in the formation of the disulfide bridges, so that the lectins cannot be linked by covalent bonds in their multimeric form. The lower size $(6 \mathrm{kDa})$ of the monomer under mild denaturing conditions with respect to that observed under reducing conditions $(11 \mathrm{kDa})$ may be the result of the compact configuration of the protein, imposed by the presence of the disulfide bridges. Results from gel chromatography support this hypothesis, as four peaks are observable, with apparent sizes of $3.5,7.5,16.8$ and $33.5 \mathrm{kDa}$, probably representing the monomeric, dimeric, tetrameric and octameric forms, respectively (Franchi et al., 2011; Gasparini et al., 2008). The three-dimensional structure of BsRBLs (Franchi et al., 2011) supports the formation of oligomers through noncovalent interactions between monomers.

Residues 1-21 represent an N-terminal signal peptide, which is removed prior to secretion as it is never found in tryptic peptide analysis. No consensus sequences for N-linked glycosylation are found, suggesting the absence of sugars in our lectin, in accordance with the majority of RBLs (Terada et al., 2007).

A phylogenetic tree built with the RBL sequences in databases clearly showed that $B s$ RBLs were located within the protochordate cluster representing the sister group of vertebrate RBLs (Gasparini et al., 2008).

\subsubsection{RBLs in B. schlosseri: Synthesis and Immune Roles}

BsRBLs are constitutively secreted, as they are always found in colony homogenates. Immunocytochemistry with an antibody against the native form of $B s \mathrm{RBL}$ indicates that professional phagocytes are the lectin-secreting cells, and they probably release BsRBLs

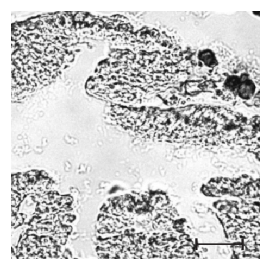

(a)

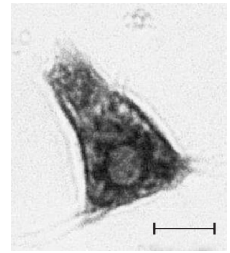

(d)

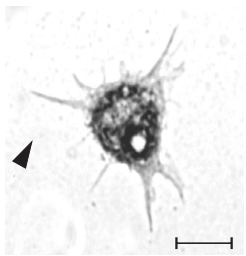

(b)

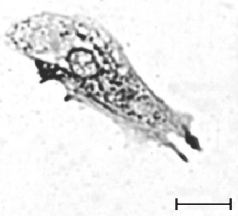

(c)

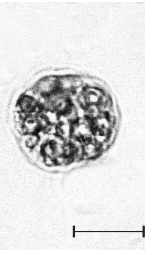

(e)

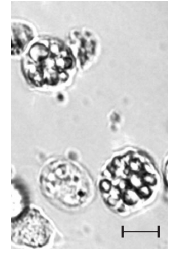

(f)

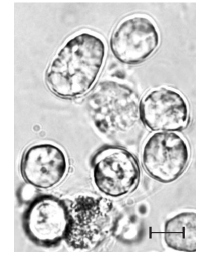

(g)

Fig. 9.7 $(a-c)$ Immunohistochemical analysis on colony sections (a), at the level of the stomach of an adult zooid and on hemocyte monolayers $(b, c)$, showing that phagocytes are the sole cells labeled by $B s R B L$. (d,e) In situ hybridization on hemocyte monolayers with antisense probe for BsRBL; only phagocytes are labeled $(d)$, whereas morula cells are unlabelled $(e)$. $(f, g)$ Living morula cells in the presence $(f)$ and absence $(\mathrm{g})$ of BsRBL. Scale bar: $50 \mu \mathrm{m}$ in (a), $10 \mu \mathrm{m}$ in $(\mathrm{b}-\mathrm{g})$. 
with an apocrine-like modality (Fig. 9.7a,b,c) (Ballarin et al., 2000). This result was confirmed by in situ hybridization with an antisense riboprobe of 460 nucleotides, as staining was restricted to hemolymph and circulating phagocytes were the only labeled cells (Fig. 9.7d) (Franchi et al., 2011).

BsRBLs change their expression during the colonial blastogenetic cycle: during the take-over a significant increase in the percentage of cells immunopositive to the antiRBL antibody was observed with respect to MC. The increase was mostly due to labeled phagocytes, but additional immunopositive cells were also labeled on their cell surface. Semiquantitative PCR confirmed the higher expression of BsRBL at take-over (Fig. 9.6d) (Franchi et al., 2011). The rise in the frequency of immunopositive cells at take-over is probably related to the massive apoptosis occurring in the tissues of old zooids during this phase of the colonial blastogenetic cycle. Previous studies (Cima et al., 2010) indicate that phagocytes change their morphology and behavior during the take-over, and $20-30 \%$ of circulating hemocytes undergo cell death. Therefore, the increase in immunolabeled cells probably has a twofold origin, deriving both from the increase in the number of phagocytes synthesizing $B s R B L$, which justifies the higher quantity of lectin mRNA at take-over, and in part from the interaction of BsRBL with the surfaces of senescent cells, as coating by BsRBL may either induce apoptosis in effete cells expressing complementary glycolipids, analogously to what is reported for catfish-egg RBL (Kawano et al., 2009; Shirai et al., 2009), or represent an 'eat me' signal for the clearance of dying cells by phagocytes.

BsRBLs can agglutinate rabbit erythrocytes (this feature was exploited for their identification during purification), yeast cells and some bacterial strains, both Gram-positive and Gram-negative, in a $\mathrm{Ca}^{2+}$-independent manner (Franchi et al., 2011). The recognition of red blood cells and yeast cells is probably mediated by the recognition of galactosides exposed on their surfaces, as endogenous rhamnose is rare in eukaryotes (Tymiak et al., 1993); the agglutination of bacteria fits the reported ability of RBLs to recognize components of the bacterial cell walls, such as lipopolysaccharides and lipoteichoic acid (Shiina et al., 2002; Tateno et al., 2002a). BsRBLs do not exert any inhibitory effects on bacterial growth (Franchi et al., 2011) and their activity towards microbial cells likely consists in increasing their visibility to phagocytes and their clearance, through phagocytosis or encapsulation. Indeed, BsRBLs can act as opsonins by increasing in vitro phagocytosis of target yeast cells (Ballarin et al., 1999, 2000; Gasparini et al., 2008). When exposed to the same $B s \mathrm{RBL}$ concentration, the morphology of phagocytes changed to a more amoeboid shape and respiratory burst was induced, with the consequent production of reactive oxygen species with microbicidal activity (Franchi et al., 2011). At lower concentrations, $B s \mathrm{RBL}$ exerts a chemotactic effect on phagocytes; this disappears at higher concentrations.

When incubated in vitro, Botryllus hemocytes release immunomodulatory molecules in the culture medium (i.e. cytokines, in the broad sense of the term), which are recognized by antibodies raised against mammalian cytokines IL1 $\alpha$ and $\mathrm{TNF} \alpha$, observable as a single band of $60 \mathrm{kDa}$ in immunoblot analysis (Fig. 9.6e). Upon exposure to BsRBL, the band markedly increased its intensity with respect to controls (incubation in filtered seawater) after 5 minutes of incubation (Franchi et al., 2011). Previous studies indicated that these molecules are synthesized and released by cytotoxic morula cells and act as cytokines on both morula cells, stimulating their migration, and phagocytes, enhancing the phagocytosis of foreign cells and the synthesis and release of BsRBLs (Menin \& Ballarin, 2008; Menin et al., 2005).

The incubation of hemocytes with $60 \mu \mathrm{g} / \mathrm{ml}$ or higher $B s \mathrm{RBL}$ led to a significant $(\mathrm{p}<0.001)$ increase in the degranulation of cytotoxic morula cells (Fig. 9.7f), with a 
consequent significant $(\mathrm{p}<0.05)$ increase of phenoloxidase activity in the culture medium (Franchi et al., 2011).

\subsubsection{BsRBL as a Multifuntional Molecule}

Collectively, all the results indicate that BsRBLs exert multiple roles in immunosurveillance and immunomodulation. During an immune response, morula cells are the first hemocytes to sense foreign molecules and release the cytokines recognized by the antiIL1 $\alpha$ and anti-TNF $\alpha$ antibodies (Menin \& Ballarin, 2008). The latter, acting in a paracrine way, induce the synthesis of $B s \mathrm{RBL}$ by a limited number of phagocytes: this allows the migration and activation of additional phagocytes towards the infection area, as BsRBL exerts chemotactic activity at low concentrations. The increased number of activated phagocytes leads to a rise of the lectin concentration, which allows the agglutination of foreign cells, favoring their clearance through phagocytosis or encapsulation, and activates morphology changes in phagocytes, rendering them more prone to phagocytosis and triggering their respiratory burst, which helps in killing microbes through the production of reactive oxygen species. In addition, analogously to the reported induction of pro-inflammatory cytokine synthesis by RBL in trout cultured cells (Ogawa et al., 2011; Watanabe et al., 2009), BsRBL potentiates the synthesis and release of cytokines by morula cells and, consequently, with a positive feedback, the progressive increase of its local concentration. When microbes are fully eliminated, the synthesis and release of cytokines by morula cells and, consequently, the secretion of lectin, probably ends. If the infection persists, as phagocytes cannot eliminate the foreign cells, the concentration of $B s \mathrm{RBL}$ reaches high levels in the circulation: this probably acts as an endogenous danger signal (Matzinger, 2002) and induces both cell death by apoptosis and morula cell degranulation. This event releases the enzyme phenoloxidase, which, acting on polyphenol substrata (also released by morula cells), induces necrotic death of all the cells within a certain area around the source of phenoloxidase (PO), thus decreasing the probability of survival of foreign cells. Fig. 9.8 summarizes these concepts.

\subsection{CONCLUSION}

The outer surface of the cell is covered by sugar molecules, which can be attached to proteins or fats. Each cell type has a unique collection of sugars, which change as the cell develops. Glycans modify the behavior of the cell by responding to external stimuli, are critical to cell-cell communications, affect the adhesion within organs, are involved in self/not-self recognition and affect susceptibility to disease, promptly interacting with various bacterial and viral intruders (see Sharon \& Lis, 2007). Glycans display a complex and branched structure, further complicated by the multiplicity of their possibilities of combination and interaction, generated by carbohydrate permutation, anomeric status, glycosidic linkage position, size of the ring and branching (Kaltner \& Gabius, 2012). The immense theoretical diversity leads to the glycome definition (collective identity of all the carbohydrates in a cell), which exceeds the proteome complexity (Gabius, 2008; Hirabayashi et al., 2001). A pattern of enzymes (glycosyltransferases, members of multigene superfamilies) modifies sugars or attaches them to proteins and lipids destined to the cell surface or extracellular compartments. Although a lectin enzymatic activity cannot be denied (Kylosov, 2008), enzymes bind to glycans to form with them multivalent 


\section{[BsRBL] $(\mu \mathrm{g} / \mathrm{ml})$}

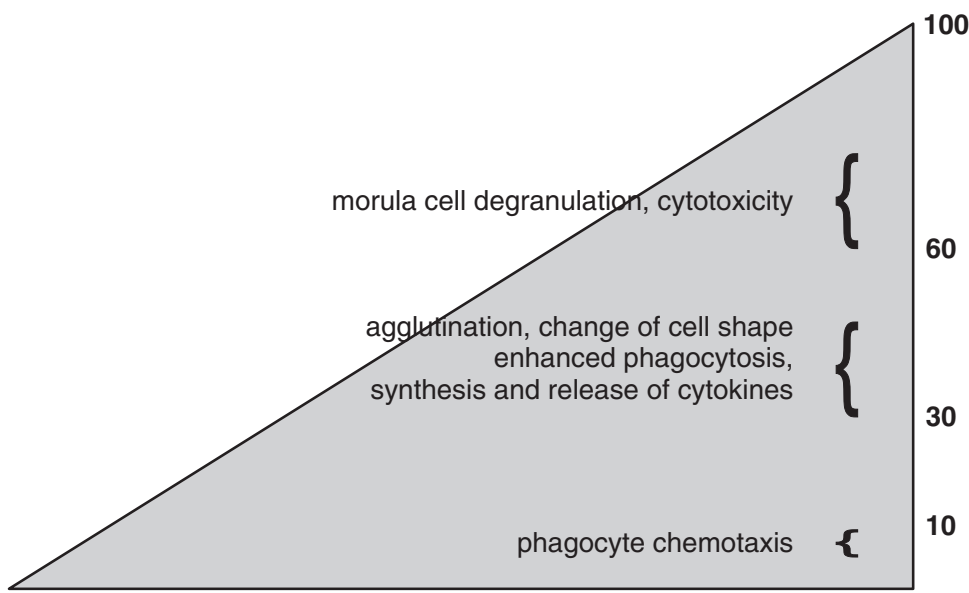

(a)

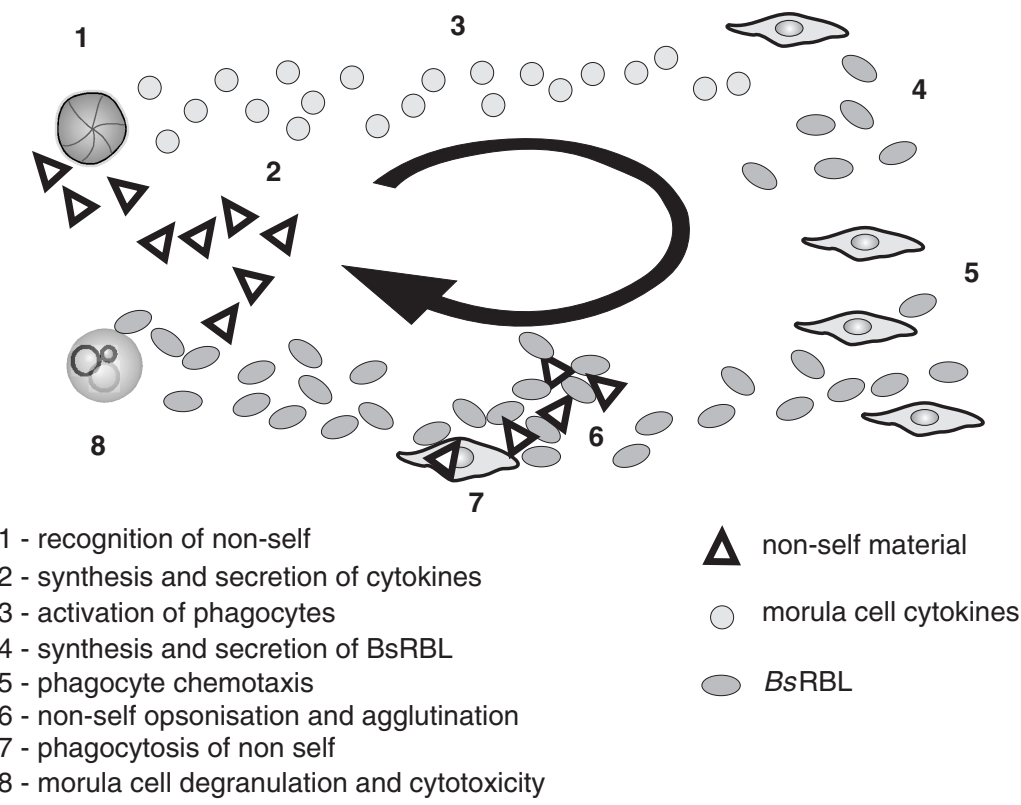

(b)

Fig. 9.8 (a) In vitro effects of various concentrations of purified BsRBL on hemocytes. (b) Sketch of proposed interactions between phagocytes and morula cells, as indicated by our results. Upon recognition of non-self molecules, morula cells release cytokines, which stimulate morula cell chemotaxis, BsRBL synthesis and secretion by phagocytes. BsRBL in turn contributes to recruitment of phagocytes to the infected site, enhances phagocytosis and the release of cytokines by morula cells and, at high concentrations, induces morula cell degranulation and consequent release of $\mathrm{PO}$, which is responsible for cytotoxicity. 
(multipoint, multicontact) noncovalent complexes without chemical modification of the ligands. In this respect, the sugar-protein recognition pattern represents an evolutionary conserved mechanism involved in a wide variety of biological processes. Accordingly, the interest given to invertebrate key models is increasing as various aspects of the lectin structure, lectin-glyconjugate interactions, signaling pathways and functions begin to be explored. cDNA and genome sequencing has facilitated the discovery of new lectins and made functional studies possible.

Ascidian lectins include galectins and rhamnose-binding proteins. Since the spectrum of galectin activities also encompasses their involvement in establishing certain features of the malignant phenotype, it is of interest to examine the evolutionary routes that have led to diversified expressions. On the other hand, RBLs constitute a new lectin family, differing from galectins in their sequence and CRD structure. Although they have not yet been found in mammals, multidomain molecules containing RBL-CRD, involved in fundamental adhesion mechanisms, have been described in various metazoans, from cnidarians to vertebrates, humans included. However, issues concerning the signaling pathways activated by the lectins upon binding to their receptor(s) require further investigation. A putative RBL receptor in fish has been identified in the Gb3 molecule, but the possibility exists that other receptors can interact with RBL-CRDs. Thus, on the grounds of immunosurveillance and growth/invasion-regulatory activity, ascidian lectins represent a promising field of study.

\section{ACKNOWLEDGEMENTS}

This work was supported by grants from the University of Padova (CPDA084343/08) and University of Palermo research projects, the Italian MIUR $(2004,2006)$ and the CARIPARO Foundation to LB.

\section{REFERENCES}

Adema, C. M., Hertel, L. A., Miller, R. D., Loker, E. S. (1997). A family of fibrinogen-related proteins that precipitates parasite-derived molecules is produced by an invertebrate after infection. Proc Natl Acad Sci USA, 94, 8691-8696.

Ahmad, N., Gabius, H. J., Andre, S., Kaltner, H., Sabesan, S., Roy, R., Liu, B., Macaluso, F., Brewer, C. F. (2004). Galectin-3 precipitates as a pentamer with synthetic multivalent carbohydrates and forms heterogeneous cross-linked complexes. J Biol Chem, 279, 10841-10847.

Ahmed, H., Vasta, G. R. (1994). Galectins: conservation of functionally and structurally relevant amino acid residues defines two types of carbohydrate recognition domains. Glycobiology, 4, 545-548.

Arason, G. J. (1996). Lectins as defense molecules in vertebrates and invertebrates. Fish Shellfish Immunol, 6, 277-289.

Arizza, V., Parrinello, D. (2009). Inflammatory hemocytes in Ciona intestinalis innate immune response. Invertebr Survival J, 6, S58-S66.

Arizza, V., Parrinello, D., Cammarata, M., Vazzana, M., Vizzini, A., Giaramita, F., Parrinello, N. (2011). A lytic mechanism based on soluble phospholypases A2 (sPLA2) and b-galactoside specific lectins is exerted by Ciona intestinalis (ascidian) unilocular refractile hemocytes against K562 cell line and mammalian erythrocytes. Fish Shellfish Immunol, 30, 1014-1023

Azumi, K., Takahashi, H., Miki, Y., Fujie, M., Usami, T., Ishikawa, H., Kitayama, A., Satou, Y., Ueno, N., Satoh, N. (2003). Construction of a cDNA microarray derived from the ascidian Ciona intestinalis. Zoolog Sci, 20, 1223-1229. 
Ballarin, L., Menin, A., Franchi, N., Bertoloni, G., Cima, F. (2005). Morula cells and non-self recognition in the compound ascidian Botryllus schlosseri. Invertebr Survival J, 2, 1-5.

Ballarin, L., Tonello, C., Guidolin, L., Sabbadin, A. (1999). Purification and characterization of a humoral opsonin with specificity for D-galactose, in the colonial ascidian Botryllus schlosseri. Comp Biochem Physiol, 123B, 115-123.

Ballarin, L., Tonello, C., Sabbadin, A. (2000). Humoral opsonin from the colonial ascidian Botryllus schlosseri as a member of the galectin family. Mar Biol, 136, 813-822.

Berril, N. J. (1955). The Origin of Vertebrates. Oxford University London Press: London.

Beschin, A., Bilej, M., Torreele, E., De Baetselier, P. (2001). On the existence of cytokines in invertebrates. Cell Mol Life Sci, 58, 801-814.

Bonura, A., Vizzini, A., Salerno, G., Parrinello, N., Longo, V., Colombo, P. (2009). Isolation and expression of a novel MBL-like collectin cDNA enhanced by LPS injection in the body wall of the ascidian Ciona intestinalis. Mol Immunol, 46, 2389-2394.

Bonura, A., Vizzini, A., Salerno, G., Parrinello, D., Parrinello, N., Longo, V., Montana, G., Colombo, P. (2010). Cloning and expression of a novel component of the CAP superfamily enhanced in the inflammatory response to LPS of the ascidian Ciona intestinalis. Cell Tissue Res, 342, 411-421.

Brewer, C. F., Miceli, M. C., Baum, L. G. (2002). Clusters, bundles, arrays and lattices: novel mechanisms for lectin-saccharide-mediated cellular interactions. Curr Opin Struct Biol, 12, 616-623.

Burighel, P., Cloney, R. A. (1997). Urochordata: Ascidiacea. In: Harrison, F. W., Ruppert, E. E., eds. Microscopic Anatomy of Invertebrates: Hemichordata, Chaetognatha and the Invertebrate Chordates, Vol. 15. Wiley-Liss: New York, pp. 221-347.

Cammarata, M., Arizza, V., Cianciolo, C., Parrinello, D., Vazzana, M., Vizzini, A., Salerno, G., Parrinello, N. (2008). The prophenoloxidase system is activated during the tunic inflammatory reaction of Ciona intestinalis. Cell Tissue Res, 333, 481-492.

Cammarata, M., Parrinello, N. (2009). The ascidian prophenoloxidase activating system. Invertebr Survival J, 6, 67-76.

Casadevall, A., Pirofski, L. A. (2000). Host-pathogen interactions: basic concepts of microbial commensalism, colonization, infection, and disease. Infect Immun, 68, 6511-6518.

Cima, F., Manni, L., Basso, G., Fortunato, E., Accordi, B., Schiavon, F., Ballarin, L. (2010). Hovering betwen death and life: haemocytes and natural apoptosis in the blastogenetic cycle of the colonial ascidian Botryllus schlosseri. Dev Comp Immunol, 34, 272-285.

Collins, B. E., Paulson, J. C. (2004). Cell surface biology mediated by low affinity multivalent protein-glycan interactions. Curr Opin Chem Biol, 8, 617-625.

Cooper, D. N. (2002). Galectinomics: finding themes in complexity. Biochim Biophys Acta, 1572, 209-231.

Cooper, D. N., Barondes, S. H. (1999). God must love galectins; he made so many of them. Glycobiology, 9, 979-984.

Delsuc, F., Brinkmann, H., Chourrout, D., Philippe, H. (2006). Tunicates and not cephalochordates are the closest living relatives of vertebrates. Nature, 439, 965-968.

Earl, L. A., Bi, S., Baum, L. G. (2011). Galectin multimerization and lattice formation are regulated by linker region structure. Glycobiology, 21, 6-12.

Franchi, N., Schiavon, F., Carletto, M., Gasparini, F., Bertoloni, G., Tosatto, S. C. E., Ballarin, L. (2011). Immune roles of a rhamnose-binding lectin in the colonial ascidian Botryllus schlosseri. Immunobiology, 216, 725-736.

Liu, F. T., Yang, R. Y., Hsu, D. K. (2012a). Galectins in acute and chronic inflammation. Ann N Y Acad Sci, 1253, 80-91.

Gabius, H. J. (1997). Animal lectins. Eur J Biochem, 243, 543-576.

Gabius, H. J. (2008). Glycans: bioactive signals decoded by lectins. Biochem Soc Trans, 36, 1491-1496.

Gabius, H. J., Wu, A. M. (2008). Galectins as regulators for tumor growth and invasion by targeting distinct cell surface glycans and implications for drug design. In: Klyosov, A. A., Witczak, Z. J., Platt, D., eds. Galectins. John Wiley \& Sons: Hoboken, NJ, pp. 71-86.

Garner, O. B., Baum, L. G. (2008). Galectin-glycan lattices regulate cell-surface glycoprotein organization and signalling. Biochem Soc Trans, 36, 1472-1477. 
Green, P., Luty, A., Nair, S., Radford, J., Raftos, D. (2006). A second form of collagenous lectin from the tunicate, Styela plicata. Comp Biochem Physiol, 144B, 343-350.

Hernandez, J. D., Baum, L. G. (2002). Ah, sweet mystery of death! Galectins and control of cell fate. Glycobiology, 12, 127-136.

Hirabayashi, J., Kasai, K. (1993). The family of metazoan metal-independent beta-galactoside-binding lectins: structure, function and molecular evolution. Glycobiology, 3, 297-304.

Hirabayashi, J., Arata, Y., Kasai, K. (2001). Glycome project: concept, strategy and preliminary application to Caenorhabditis elegans. Proteomics, 1, 295-303.

Hirabayashi, J., Hashidate, T., Arata, Y., Nishi, N., Nakamura, T., Hirashima, M., Urashima, T., Oka, T., Futai, M., Muller, W. E. G., Yagi, F., Kasai, K. (2002). Oligosaccharide specificity of galectins: a search by frontal affinity chromatography. Biochim Biophys Acta, 1572, 232-254.

Houzelstein, D., Gonçalves, I. R., Fadden, A. J., Sidhu, S. S., Cooper, D. N., Drickamer, K., Leffler, H., Poirier, F. (2004). Phylogenetic analysis of the vertebrate galectin family. Mol Biol Evol, 21, $1177-1187$.

Hwang, J. S., Takaku, Y., Momose, T., Adamczyk, P., Özbek, S., Ikeo, K., Khalturin, K., Hemmrich, G., Bosch, T. C., Holstein, T. W., David, C. N., Gojobori, T. (2010). Nematogalectin, a nematocyst protein with GlyXY and galectin domains, demonstrates nematocyte-specific alternative splicing in Hydra. Proc Natl Acad Sci USA, 107, 18539-18544.

Ji, W. Z., Shang, N., Guo, Q.L. (2009). Molecular cloning of rhamnose-binding gene and its promoter region from snakehead Channa argus. Fish Physiol Biochem, 36, 451-459.

Jimbo, M., Usui, R., Sakai, R., Muramoto, K., Kamiya, H. (2007). Purification, cloning and characterization of egg lectins from the teleost Tribolodon brandti. Comp Biochem Physiol, 147B, 164-171.

Kaltner, H., Gabius, H. J. (2012). A toolbox of lectins for translating the sugar code: the galectin network in phylogenesis and tumors. Histol Histopathol, 27, 397-416.

Kaltner, H., Stierstorfer, B. (1998). Animal lectins as cell adhesion molecules. Acta Anat (Basel), 161, $162-179$.

Kawano, T., Sugawara, S., Hosono, M., Tatsuta, T., Ogawa, Y., Fujimura, T., Taka, H., Murayama, K., Nitta, K. (2009). Globotriaosylceramide-expressing Burkitt's lymphoma cells are committed to early apoptotic status by rhamnose-binding lectin from catfish eggs. Biol Pharm Bull, 32, 345-353.

Kinjo, A., Takahashi, M., Matsushita, M., Endo, Y., Nakata, M., Mizuochi, T., Fujita, T. (2001). Cloning and characterization of novel ficolins from the solitary ascidian, Halocynthia roretzi. J Biol Chem, 276, 19959-19965.

Kilpatrick, C. D. (2002). Animal lectins: a historical introduction and overview. Biochim Biophys Acta, 1572, 187-197.

Klyosov, A. A. (2008). Galectins and their functions in plain language. In: Klyosov, A. A., Witczak, Z. J., Platt, D., eds. Galectins. John Wiley \& Sons: Hoboken, NJ, pp. 9-32.

Lam, Y. W., Ng, T. B. (2002). Purification and characterization of a rhamnose-binding lectin with immunoenhancing activity from grass carp (Ctenopharyngodon idellus) ovaries. Protein Expres Purif, 26, 378-385.

Lauzon, R. J., Ishikuza, K. J., Weissman, I. L. (1992). A cyclical, developmentally-regulated death phenomenon in a colonial urochordate. Dev Dyn, 194, 71-83.

Levroney, E. L., Aguilar, H. C., Fulcher, J. A., Kohatsu, L., Pace, K. E., Pang, M., Gurney, K. B., Baum, L. G., Lee, B. (2005). Novel innate immune functions for galectin-1, galectin-1 inhibits cell fusion by Nipah virus envelope glycoproteins and augments dendritic cell secretion of proinflammatory cytokines. J Immunol, 175, 413-420.

Liu, F. T., Hsu, D. K., Yang, R.-Y., Chen, H.-Y., Saegusa, J. (2008). Galectins in regulation of inflammation and immunity. In: Klyosov, A. A., Witczak, Z. J., Platt, D., eds. Galectins. John Wiley \& Sons: Hoboken, NJ, pp. 97-113.

Liu, F. T., Yang, R. Y., Hsu, D. K. (2012b). Galectins in acute and chronic inflammation. Ann N Y Acad Sci, 1253, 80-91.

López, J. A., Fain, M. G., Cadavid, L. F. (2011). The evolution of the immune-type gene family Rhamnospondin in cnidarians. Gene, 473, 119-124 
Loris, R. (2002). Principles of structures of animal and plant lectins. Biochim Biophys Acta, 1572, $198-208$.

Manni, L., Zaniolo, G., Cima, F., Burighel, P., Ballarin, L. (2007). Botryllus schlosseri: a model ascidian for the study of asexual reproduction. Dev Dyn, 236, 335-352.

Marino, R., Kimura, Y., De Santis, R., Lambris, J. D., Pinto, M. R. (2002). Complement in urochordates: cloning and characterization of two $\mathrm{C} 3$-like genes in the ascidian Ciona intestinalis. Immunogenetics, $53,1055-1064$.

Matsui, T., Ozeki, Y., Suzuki, M., Hino, A., Titani, K. Purification and characterization of two $\mathrm{Ca}^{2+}-$ dependent lectins from coelomic plasma of sea cucumber, Stychopus japonicus. J Biochem, 116, $1127-1133$

Matzinger, P. (2002). The danger model: a renewed sense of self. Science 296, 301-305.

Menin, A., Ballarin, L. (2008). Immunomodulatory molecules in the compound ascidian Botryllus schlosseri: evidence from conditiooned media. J Invertebr Pathol, 99, 275-280.

Menin, A., Del Favero, M., Cima, F., Ballarin, L. (2005). Release of phagocytosis-stimulating factor(s) by morula cells in a colonial ascidian. Mar Biol, 148, 225-230.

Miyazawa, S., Azumi, K., Nonaka, M. (2001).Cloning and characterization of integrin alpha subunits from the solitary ascidian, Halocynthia roretzi. J Immunol, 166, 1710-1715.

Ng, T. B., Lam, Y. W., Woo, N. Y. (2003). The immunostimulatory activity and stability of grass carp (Ctenopharyngodon idellus) roe lectin. Vet Immunopathol, 94, 105-112.

Nonaka, M., Azumi, K. (1999). Opsonic complement system of the solitary ascidian, Halocynthia roretzi. Dev Comp Immunol, 23, 421-427.

Ogawa, T., Watanabe, M., Naganuma, T., Muramoto, K. (2011). Diversified carbohydrate-binding lectins from marine resources. J Amino Acids, 2011, 838914.

Ozaki, H., Ohwaki, M., Fukuda, T. 1983. Studies on lectins of amago (Onchorhynchus rhodurus) I. Amago ova lectin and its receptor on homologous macrophages. Dev Comp Immunol, 7, 77-87.

Ozeki, Y., Matsui, T., Suzuki, M., Titani, K. (1991). Amino acid sequence and molecular characterization of a D-galactoside-specific lectin purified from sea urchin (Anthocidaris crassispina) eggs. Biochemistry, 30, 2391-2394.

Pancer, Z., Diehl-Seifert, B., Rinkevich, B., Müller, W. E. (1997). A novel tunicate (Botryllus schlosseri) putative C-type lectin features an immunoglobulin domain. DNA Cell Biol, 16, 801-806.

Parrinello, N., Patricolo, E., Canicattì, C. (1984a). Inflammatory-like reaction in the tunic of Ciona intestinalis (Tunicata). Encapsulation and Tissue Injury I. Biol Bull, 167, 229-237.

Parrinello, N., Patricolo, E., Canicattì, C. (1984b). Inflammatory-like reaction in the tunic of Ciona intestinalis (Tunicata). Encapsulation Tissue Injury II. Biol Bull, 167, 238-250.

Parrinello, N., Arizza, V., Cammarata, M., Giaramita, F. T., Pergolizzi, M., Vazzana, M., Vizzini, A., Parrinello, D. (2007). Inducible lectins with galectin properties and human IL1alpha epitopes opsonize yeast during the inflammatory response of the ascidian Ciona intestinalis. Cell Tissue Res, 329, 379-390.

Parrinello, N., Vizzini, A., Arizza, V., Salerno, G., Parrinello, D., Cammarata, M., Giaramita, F. T., Vazzana, M. (2008). Enhanced expression of a cloned and sequenced Ciona intestinalis TNF $\alpha$-like $($ CiTNF $\alpha$ ) gene during the LPS-induced inflammatory response. Cell Tissue Res, 334, 305-317.

Parrinello, N., Vizzini, A., Salerno, G., Sanfratello, M. A., Cammarata, M., Arizza, V., Vazzana, M., Parrinello, D. (2010). Inflamed adult pharynx tissues and swimming larva of Ciona intestinalis share CiTNF $\alpha$-producing cells. Cell Tissue Res, 341, 299-311.

Parrinello, N. (1995). Humoral and cellular lectins of ascidians. J Mar Biotechnol, 3, 29-34.

Parrinello, N. (1981). The reaction of Ciona intestinalis L. to subcuticular erythrocyte and protein injection. Dev Comp Immunol, 5, 105-110.

Parsonage, G., Trebilcock, E., Toscano, M. A., Bianco, G. A., Ilarregui, J. M., Buckley, C. D., Rabinovich, G. A. (2006). Roles of galectins in chronic inflammatory microenvironments. Future Rheumatol, 1, 441-454.

Paulson, J. C., Blixt, O., Collins, B. E. (2006). Sweet spots in functional glycomics. Nat Chem Biol, 2, $238-248$. 
Peddie, C. M., Riches, A. C., Smith, V. J. (1995). Proliferation of undifferentiated blood cells from the solitary ascidian, Ciona intestinalis in vitro. Dev Comp Immunol, 19, 377-387.

Pinto, M. R., Chinnici, C. M., Kimura, Y., Melillo, D., Marino, R., Spruce, L. A., De Santis, R., Parrinello, N., Lambris, J. D. (2003). CiC3-1 mediated chemotaxis in the deuterostome invertebrate Ciona intestinalis (Urochordata). J Immunol, 171, 5521-5528.

Quesenberry, M. S., Ahmed, H., Elola, M. T., O’Leary, N., Vasta, G. R. (2003). Diverse lectin repertoires in tunicates mediate broad recognition and effector innate immune responses. Integr Comp Biol, 43, $323-330$.

Rabinovich, G. A., Toscano, M. A. (2009). Turning 'sweet' on immunity: galectin-glycan interactions in immune tolerance and inflammation. Nat Rev Immunol, 9, 338-352.

Rabinovich, G. A., Toscano, M. A., Jackson, S. S., Vasta, G. R. (2007). Functions of cell surface galectin-glycoprotein lattices. Curr Opin Struct Biol, 17, 513-520.

Raftos, D., Green, P., Mahajan, D., Newton, R., Pearce, S., Peters, R., Robbins, J., Nair, S. (2001). Collagenous lectins in tunicates and the proteolytic activation of complement. Adv Exp Med Biol, 484, 229-236.

Rapoport, E. M., Kurmyshkina, O. V., Bovin, N. V. (2008). Mammalian galectins: structure, carbohydrate specificity, and functions. Biochemistry (Mosc), 73, 393-405.

Rini, J. M., Lobsanov, Y. D. (1999). New animal lectin structures. Curr Opin Struct Biol, 9, 578-584.

Rodriguez-Boulan, E., Gonzalez, A. (1999). Glycans in post-Golgi apical targeting: sorting signals or structural props? Trends Cell Biol, 9, 291-294.

Sato, S., Rabinovich (2008). Galectins as danger signals in host-pathogen and host-tumor interactions: new members of the growing group of 'alarmins'? In: Klyosov, A. A., Witczak, Z. J., Platt, D., eds. Galectins. John Wiley \& Sons: Hoboken, NJ, pp. 115-145.

Schwarz, R. S., Hodes-Villamar, L., Fitzpatrick, K. A., Fain, M. G., Hughes, A. L., Cadavid, L. F. (2007). A gene family of putative immune recognition molecules in the hydroid Hydractinia. Immunogenetics, $59,233-246$.

Sekine, H., Kenjo, A., Azumi, K., Ohi, G., Takahashi, M., Kasukawa, R., Ichikawa, N., Nakata, M., Mizuochi, T., Matsushita, M., Endo, Y., Fujita, T. (2001). An ancient lectin-dependent complement system in an ascidian: novel lectin isolated from the plasma of the solitary ascidian, Halocynthia roretzi. J Immunol, 167, 4504-4510.

Sharon, N., Lis, H. (1993). Carbohydrates in cell recognition. Sci Am, 268, 82-89.

Sharon, N., Lis, H. (2007). Lectins (2nd edition). Springer: Dordrecht, Netherlands.

Shiina, N., Tateno, H., Ogawa, T., Muramoto, K., Saneyoshi, M., Kamiya, H. (2002). Isolation and characterization of L-rhamnose-binding lectins from chum salmon (Onchorynchus keta) eggs. Fish Sci, 68, 1352-1366.

Shirai, T., Watanabe, Y., Lee, M., Ogawa, T., Muramoto, K. (2009). Structure of rhamnose-binding lectin CSL3, unique pseudo-tetrameric architecture of a pattern recognition protein. J Mol Biol, 391, 390-403.

Tasumi, S., Vasta, G. R. (2007). A galectin of unique domain organization from hemocytes of the eastern oyster (Crassostrea virginica) is a receptor for the protistan parasite Perkinsus marinus. J Immunol, 179, 3086-3098.

Tateno, H., Saneyoshi, A., Ogawa, T., Muramoto, K., Kamiya, H., Saneyoshi, M. (1998). Isolation and characterization of rhamnose-binding lectins from eggs of steelhead trout (Onchorynchus mykiss) homologous to low density lipoprotein receptor superfamily. J Biol Chem, 273, 19190-19197.

Tateno, H., Ogawa, T., Muramoto, K., Kamiya, H., Saneyoshi, M. (2002a). Rhamnose-binding lectins from steelhead trout (Onchorynchus mykiss) eggs recognize bacterial lipopolysaccharides and lipoteichoic acid. Biosci Biotechnol Biochem, 66, 604-612.

Tateno, H., Ogawa, T., Muramoto, K., Kamiya, H., Saneyoshi, M. (2002b). Distribution and molecular evolution of rhamnose-binding lectins in Salmonidae: isolation and characterization of two lectins from white-spotted charr (Salvelinus leucomaenis) eggs. Biosci Biotechnol Biochem, 66, 1356-1365.

Teichberg, V. I., Silman, I., Beitsch, D. D., Resheff, G. (1975). A $\beta$-D-galactoside binding protein from electric organ tissue of Electrophorus electricus. Proc Natl Acad Sci USA, 72, 1383-1387. 
Terada, T., Watanabe, Y., Tateno, H., Naganuma, T., Ogawa, T., Muramoto, K., Kamiya, H. (2007). Structural characterization of a rhamnose binding glycoprotein (lectin) from Spanish mackerel (Scomberomorous niphonius) eggs. Biochim Biophys Acta, 1770, 617-629.

Terajima, D., Yamada, S., Uchino, R., Ikawa, S., Ikeda, M., Shida, K., Arai, Y., Wang, H. G., Satoh, N., Satake, M. (2003a). Identification and sequence of seventy-nine new transcripts expressed in hemocytes of Ciona intestinalis, three of which may be involved in characteristic cell-cell communication. DNA Res, 10, 203-212.

Terajima, D., Shida, K., Takada, N., Kasuya, A., Rokhsar, D., Satoh, N., Satake, M., Wang, H. G. (2003b). Identification of candidate genes encoding the core components of the cell death machinery in the Ciona intestinalis genome. Cell Death Differ, 10, 749-753.

Tsagkogeorga, G., Turon, X., Hopcroft, R. R., Tilak, M. K., Feldstein, T., Shenkar, N., Loya, Y., Huchon, D., Douzery, E. J. P., Delsuc, F. (2009). An updated 18S rRNA phylogeny of tunicates based on mixture and secondary structure models. BMC Evol Biol, 9, 187.

Tymiak, A. A., Norman, J. A., Bolgar, M., Di Donato, G. C., Lee, H., Parker, W. L., Lo, L. C., Berova, N., Nakanishi, K., Haber, E. (1993). Physicochemical characterization of a ouabain isomer isolated from bovine hypothalamus. Proc Natl Acad Sci USA, 90, 8189-8193.

Vakonakis, I., Langhenhan, T., Prömel, S., Russ, A., Campbell, I. D. (2008). Solution structure and sugar-binding mechanism of mouse latrophilin-1 RBL: a 7TM receptor-attached lectin-like domain. Structure, 16, 944-953.

Van der Holst, P. P., Schlaman, H. R., Spaink, H.P. (2001). Proteins involved in the production and perception of oligosaccharides in relation to plant and animal development. Curr Opin Struct Biol, 11, $608-616$.

Vasta, G. R. (2012). Galectins as pattern recognition receptors: structure, function, and evolution. Adv Exp Med Biol, 946, 21-36.

Vasta, G., Jeffrey, C., Hunt, J., Marchalonis, J., Wayne, W. (1986). Fish galactosyl-binding lectins from the tunicate Didemnum candidum: purification and physicochemical characterization. J Biol Chem, 261, 9174-9181.

Vasta, G. R., Ahmed, H., Fink, N. E., Elola, M. T., Marsh, A. G., Snowden, A., Odom, E. W. (1994). Animal lectins as self/non-self recognition molecules. Biochemical and genetic approaches to understanding their biological roles and evolution. Ann N Y Acad Sci, 712, 55-73

Vasta, G. R., Ahmed, H., Odom, E. W. (2004). Structural and functional diversity of lectin repertoires in invertebrates, protochordates and ectothermic vertebrates. Curr Opin Struct Biol, 14, 617-630.

Vasta, G. R., Quesenberry, M., Ahmed, H., O’Leary, N. (1999). C-type lectins and galectins mediate innate and adaptive immune functions: their roles in the complement activation pathway. Dev Comp Immunol, 23, 401-420.

Vizzini, A., Parrinello, D., Sanfratello, M. A., Salerno, G., Cammarata, M., Parrinello, N. (2012). Inducible galectins are expressed in the inflamed pharynx of the ascidian Ciona intestinalis. Fish Shellfish Immunol, 32, 101-109.

Vizzini, A., Pergolizzi, M., Vazzana, M., Salerno, G., Di Sano, C., Macaluso, P., Arizza, V., Parrinello, D., Cammarata, M., Parrinello, N. (2008). FACIT collagen (1alpha-chain) is expressed by hemocytes and epidermis during the inflammatory response of the ascidian Ciona intestinalis. Dev Comp Immunol, 32, 682-692.

Vizzini, A., Arizza, V., Cervello, M., Cammarata, M., Gambino, R., Parrinello, N. (2002). Cloning and expression of a type IX-like collagen in tissues of the ascidian Ciona intestinalis. Biochim Biophys Acta, 1577, 38-44.

Watanabe, Y., Tateno, H., Nakamura-Tsuruta, S., Kominami, J., Hirabayashi, J., Nakamura, O., Watanabe, T., Kamiya, H., Naganuma, T., Ogawa, T., Naudé, R. J., Muramoto, K. (2009). The function of rhamnose-binding lectin in innate immunity by restricted binding to Gb3. Dev Comp Immunol, 33, $187-197$.

Watkins, W. M., Morgan, W. T. (1952). Neutralization of the anti-H agglutinin in eel serum by simple sugars. Nature, 169, 825-826.

Yang, R. Y., Rabinovich, G. A., Liu, F. T. (2008). Galectins: structure, function and therapeutic potential. Exp Rev Mol Med, 13, 10-17. 
